\title{
Giardia spp. e Cryptosporidium spp. em água de manancial superficial de abastecimento contaminada por dejetos humano e animal
}

\author{
[Giardia spp. and Cryptosporidium spp. in a fresh water supply source contaminated with human \\ and animal excreta and waste water]

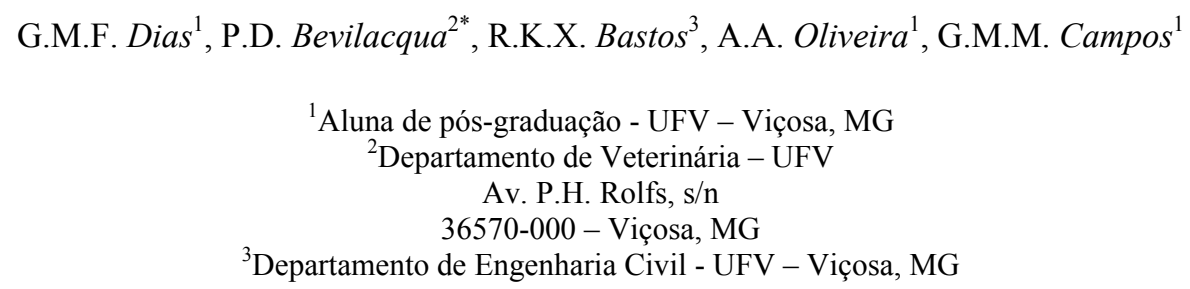

\begin{abstract}
RESUMO
Estudou-se ocorrência de cistos de Giardia spp. e oocistos de Cryptosporidium spp. - (oo)cistos - na bacia hidrográfica do Ribeirão São Bartolomeu, localizada no município de Viçosa, MG. O estudo incluiu as populações humana e animal existentes na área da bacia, bem como no efluente de uma estação de tratamento de esgoto (ETE) e de duas instalações para suínos. Os resultados indicam presença de (oo)cistos no manancial (médias geométricas: 3,92 e 3,62 (oo)cistos/1 para Giardia spp. e Cryptosporidium spp., respectivamente). Propriedades com exploração bovina foram positivas ao longo de todo período (prevalência média de propriedades positivas 36,4\% para Giardia spp. e 18,0\% para Cryptosporidium spp.). O efluente da ETE apresentou elevada concentração de cistos de Giardia spp. (média geométrica na ordem de $10^{4} / 1$ ), mas não foram encontrados oocistos de Cryptosporidium spp. A ocorrência de (oo)cistos apresentou comportamento sazonal, sendo que os valores médios de (oo)cistos e de pluviosidade do trimestre de coleta revelaram bom ajuste de correlação $\left(\mathrm{R}^{2}=98,3 \% ; \mathrm{P}=0,0087\right.$ para Giardia spp. e $\mathrm{R}^{2}=91,8 \% ; \mathrm{P}=0,0421$ para Cryptosporidium spp.). A significativa ocorrência de (oo)cistos no manancial sugere que a forma de ocupação do solo interfere na qualidade parasitológica da água bruta. Os resultados apontam para a importância de adoção de medidas preventivas, como proteção de áreas de mananciais, objetivando reduzir riscos de transmissão de protozoários via água de consumo humano.
\end{abstract}

Palavras-chave: água, manancial de abastecimento, Giardia spp., Cryptosporidium spp., qualidade da água

\begin{abstract}
The occurrence of Giardia spp. cysts and Cryptosporidium spp. oocysts - (oo)cysts - was studied in a watershed (São Bartolomeu Stream-SB), at Viçosa city, MG. In the studied area, characterization of animal farms and identification of sewage and animal wastes discharges were undertaken. In addition, a sewage treatment plant (STP) and effluents of two swine farms were sampled. The results presented protozoan contamination (geometric averages: 3.92 and 3.62 (oo)cysts/l for Giardia spp. and Cryptosporidium spp., respectively). Positive cattle farms were detected during all the period, and the correspondent mean prevalences were: $36.4 \%$ for Giardia spp. and 18.0\% for Cryptosporidium spp. STP effluent presented high concentration of Giardia spp. (geometric average of cysts in the order of $10^{4} / \mathrm{l}$ ). However, Cryptosporidium spp. oocysts were not detected. The results showed that (oo)cysts concentration were influenced by climate factors. Precipitation and (oo)cysts concentration data were well correlated $\left(R^{2}=98.3 \%\right.$; $P=0.0087$ for Giardia spp. and $R^{2}=91.8 \%$; $P=0.0421$ for Cryptosporidium spp.). Cysts and oocysts levels were remarkably high in the raw water source, pointing out the role of
\end{abstract}

Recebido em 9 de outubro de 2007

Aceito em 2 de setembro de 2008

Autor para correspondência (corresponding author)

E-mail: paula@ufv.br 
land use in an unprotected watershed as a source of protozoa. The results demonstrate the importance of preventive measures rather than relying on, sometimes unreliable, corrective measures such as water treatment, in order to minimize human health risks.

Keywords: water, watershed, Giardia spp., Cryptosporidium spp., water quality

\section{INTRODUÇÃO}

O uso inadequado, e muitas vezes irracional, dos recursos hídricos disponíveis reflete o atual quadro de escassez e deterioração da qualidade da água. O não tratamento ou tratamento inadequado dos resíduos sólidos e das águas residuárias provocam a contaminação, por diferentes tipos de organismos, de mananciais de água usados para consumo humano. A associação entre o consumo de água contaminada e a transmissão de enteroparasitas, a exemplo de Giardia spp., é, há muito tempo, bem esclarecida. Posteriormente, foi constatado que espécies de Cryptosporidium também são veiculadas pela água, sendo a criptosporidiose considerada doença emergente, com ampla distribuição geográfica, tendo sido registrados diversos surtos e infecções esporádicas em várias partes do mundo. Esses parasitas são alvo de preocupações recentes, tanto das autoridades de saúde pública quanto da comunidade científica, devido à transmissão comprovada de cistos de Giardia spp. e oocistos de Cryptosporidium spp. mediante consumo de água tratada e distribuída por sistemas de abastecimento (Allen et al., 2000; Fayer et al., 2000; Gamba et al., 2000; Kosek et al., 2001; Tzipori e Ward, 2002).

A crescente preocupação com a transmissão de protozoários via abastecimento de água para consumo humano envolve ainda as seguintes dificuldades na busca de equacionamento do problema: (i) reconhecimento das limitações dos processos convencionais de tratamento de água na remoção/inativação de cistos de Giardia spp. e oocistos de Cryptosporidium spp. (Nieminsky e Ongerth, 1995); (ii) insuficiência do controle tradicional da qualidade da água tratada por detecção de bactérias do grupo coliformes ou outros indicadores (Bastos et al., 2000); (iii) limitações analíticas dos métodos disponíveis de pesquisa de protozoários em amostra de água (Allen et al., 2000); (iv) dificuldade de estimar riscos à saúde associados à presença de cistos de Giardia spp. e oocistos de Cryptosporidium spp. em águas de consumo humano, principalmente quando em números reduzidos (Craun et al., 1998).

O potencial zoonótico desses protozoários ainda não está totalmente elucidado. $\mathrm{Na}$ realidade, persistem dúvidas sobre os reservatórios animais de Giardia spp. e Cryptosporidium spp. pela dificuldade de distinção de organismos espécieespecíficos (Ramirez et al., 2004; Xiao et al., 2004).

Estudo realizado anteriormente demonstrou a existência de Giardia spp. e Cryptosporidium spp. em um dos mananciais de abastecimento do município de Viçosa-MG em densidades de 7,0140 cistos $/ 1$ e 7,98-510 oocistos/l, respectivamente. Em todas as amostras com presença de Giardia spp. e Cryptosporidium spp., as densidades superaram, em muito, os níveis de alerta sugeridos na literatura. Em tese, estar-se-ia perante riscos elevados de infecção (Bastos et al., 2001). Estudos epidemiológicos sobre ocorrência de Giardia spp. e Cryptosporidium spp. no município têm revelado prevalência de infecção de 2,7\% para o primeiro e ausência de infecção para o segundo (Heller et al., 2004; Oliveira, 2004).

Considerando o exposto, o objetivo deste trabalho foi avaliar o papel da exploração animal e da população humana assentada na área da bacia hidrográfica de um manancial de abastecimento para consumo humano na contaminação da água.

\section{MATERIAL E MÉTODOS}

A bacia hidrográfica do Ribeirão São Bartolomeu (RSB) abrange uma área de, aproximadamente 5.534 hectares, localizada no município de Viçosa, pertencente à Zona da Mata de Minas Gerais. A área de estudo compreendeu a bacia hidrográfica a montante do município, em uma extensão de aproximadamente 605 hectares, caracterizada por intensa atividade agropecuária desenvolvida por pequenos produtores rurais e, mais recentemente, 
expansão urbana, com a implantação paulatina de condomínios e loteamentos. Nessa região, o RSB recebe o aporte hídrico de sete córregos, a partir dos quais se delimitaram as sub-bacias monitoradas, nomeadas a partir da denominação do curso d'água principal: sub-bacia 1: Córrego São Lucas, sub-bacia 2: Córrego dos Machados, sub-bacia 3: Córrego Santa Catarina, sub-bacia 4: Córrego Paraíso, sub-bacia 5: Córrego Palmital, sub-bacia 6: Córrego Antuérpia, subbacia 7: Córrego do Engenho. Após definição das sub-bacias, procedeu-se, em cada uma delas, ao levantamento de todas as propriedades rurais com exploração animal. Adicionalmente, identificaram-se pontos de descarga de esgotos sanitários nos cursos d'água para coleta e análise de amostras.

Foram selecionados oito pontos para coleta de água na bacia hidrográfica do RSB para o monitoramento da qualidade parasitológica, sete pontos referiam-se às sete sub-bacias, e um ponto ao próprio RSB (Fig. 1). A pesquisa de cistos de Giardia spp. e oocistos de Cryptosporidium spp. foi realizada por meio da coleta de amostras de água (101), concentração pela técnica de floculação com carbonato de cálcio (Vesey et al., 1993) e enumeração com imunofluorescência direta $^{1}$. Os pontos foram monitorados trimestralmente, entre janeiro de 2003 e janeiro de 2004, em paralelo às coletas de material fecal. Adicionalmente, foram coletadas amostras dos efluentes brutos de duas instalações de suínos e do efluente de uma ETE localizada no bairro Romão dos Reis, o qual é lançado no RSB após tratamento por tanque séptico-filtro anaeróbio.

Foi realizado levantamento das propriedades rurais que desenvolviam atividades de exploração animal, para a coleta de material fecal. Na ausência de sinais clínicos, as fezes foram acondicionadas em conjunto,

\footnotetext{
${ }^{1}$ Meridian Diagnostics, Inc., Cincinnati, Ohio, EUA. O reagente de detecção do kit Merifluor ${ }^{\circledR}$ contém uma mistura de anticorpos monoclonais marcada com FITC direcionados contra os antígenos da parede celular de cistos de Giardia spp. e oocistos de Cryptosporidium spp., cuja diferenciação se dá por aspectos morfológicos e tamanho (cistos de Giardia spp. $8-12 \mu \mathrm{m}$ e oocistos de Cryptosporidium spp. 4-6 $\mu \mathrm{m})$. A sensibilidade do kit varia de $97-100 \%$ e a especificidade de 94-100\% para Cryptosporidium spp. e para Giardia spp., ambas são de $100 \%$ (MeriFluor ${ }^{\circledR}$ Cryptosporidium/Giardia, 2004)
}

representando uma amostra da propriedade; se, porventura, existissem animais com sinais clínicos de doença gastroentérica, as amostras fecais eram coletadas e analisadas separadamente. No primeiro momento de coleta, foi aplicado questionário para levantamento de informações referentes às fontes de água fornecida aos animais, ao destino dos dejetos, à idade e ao manejo para caracterização da população animal e definição de fatores de risco associados à infecção. A pesquisa de cistos de Giardia spp. e oocistos de Cryptosporidium spp. foi realizada por meio da metodologia de Faust e coloração de Ziehl Neelsen modificada, respectivamente. As propriedades foram acompanhadas durante o período de um ano (iniciado em janeiro de 2003), sendo coletadas amostras fecais trimestrais dos animais existentes no local.

Foram calculadas as prevalências de propriedades positivas para protozoários, as quais foram comparadas por tabelas de contingência e pelo teste do qui-quadrado $\left(\chi^{2}\right)$. Os resultados da ocorrência de (oo)cistos de protozoários em amostras de água foram discutidos a partir do cálculo de médias geométricas por período e por sub-bacia, sendo os mesmos acrescidos do valor 1, devido à ocorrência de resultados nulos. Para as comparações entre as médias geométricas de protozoários, inicialmente os dados foram testados para normalidade (teste Liliefors) e homocedasticidade (teste Barttlet); quando possível, foi utilizada a técnica de análise de variância, seguida do teste Tukey; quando a distribuição se mostrou não normal, optou-se pelo teste Wilcoxon ou Kruskal Wallis. Estudos de correlações entre as ocorrências de (oo)cistos e pluviosidade média referentes à semana de coleta da amostra foram realizados pelo cálculo do coeficiente de Pearson $\left(\mathrm{R}^{2}\right)$.

As análises foram efetuadas no pacote estatístico SAEG (Sistema..., 2007). Em todas as interpretações, adotou-se como nível de significância $\alpha=5 \%$. 


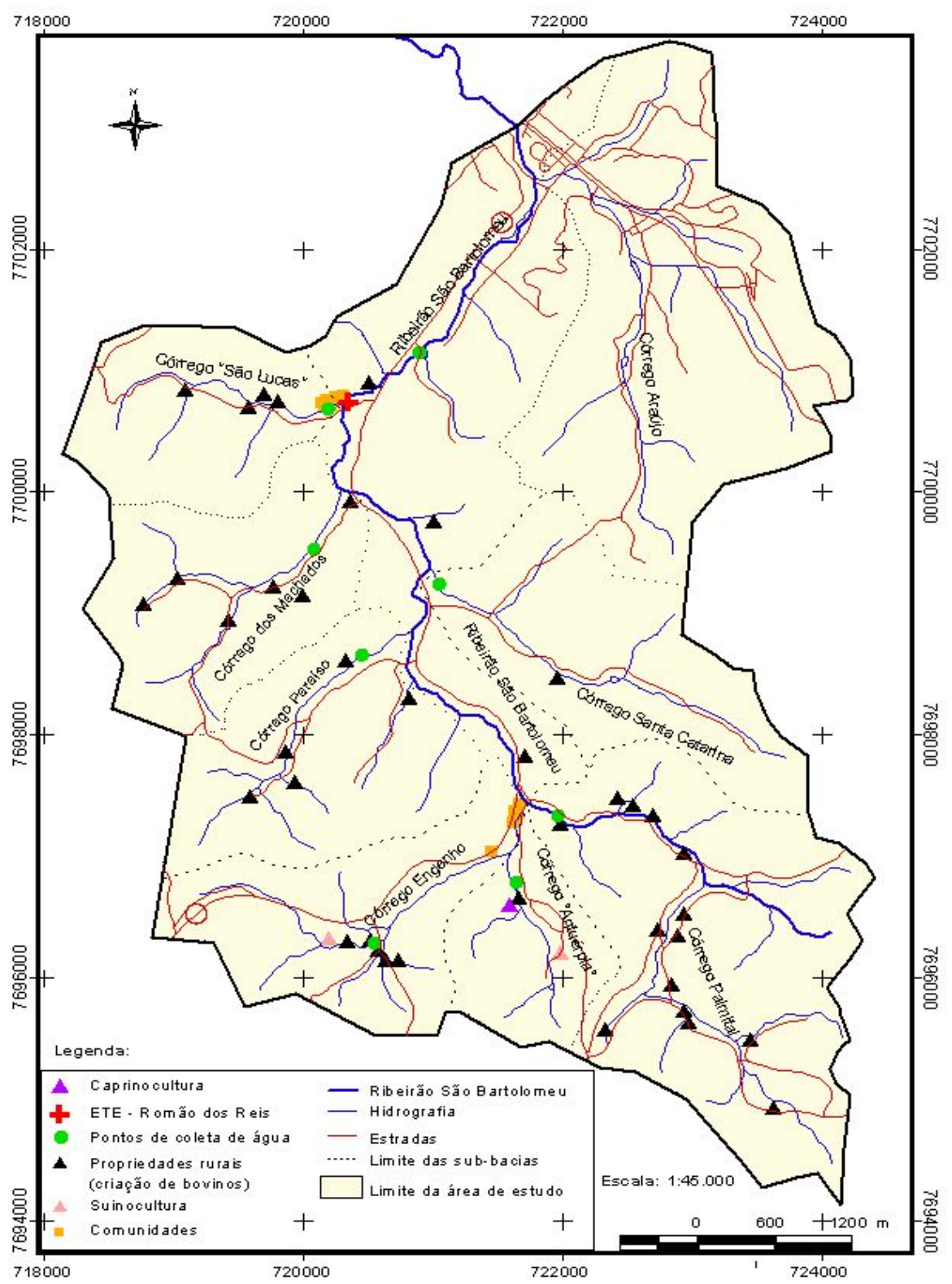

Figura 1. Localização dos pontos de coleta de água e propriedades rurais estudadas na bacia hidrográfica do Ribeirão São Bartolomeu, Viçosa, MG, janeiro de 2003 a janeiro de 2004.

\section{RESULTADOS E DISCUSSÃO}

O levantamento das propriedades existentes na bacia hidrográfica do RSB revelou a existência de 42 propriedades com exploração animal, sendo que $41(97,6 \%)$ delas participaram da pesquisa. Desse total, $38(92,7 \%)$ exploravam bovinos (aproximadamente 300 animais ao todo); duas $(4,9 \%)$ suínos (cerca de 250 e 620 animais) e uma $(2,4 \%)$ caprinos (cerca de 40 animais). A área estudada apresentou alta densidade de suínos, embora a maior porcentagem das propriedades explorasse bovinos.

Com relação ao manancial de água utilizado para dessedentação dos animais, $73,8 \%$ das propriedades ofereciam água proveniente de manancial subterrâneo e 26,2\%, água de manancial superficial (Tab. 1). Esses dados 
referem-se à água oferecida aos animais no estábulo. Nas pastagens, os bovinos utilizavam a água de córregos e ribeirões que porventura passassem pela propriedade. Isso sugere que os animais podem se contaminar ao beber água do manancial superficial e, conseqüentemente, contaminar os cursos d'água ao eliminarem fezes contendo (oo)cistos de protozoários.

Adicionalmente, os mananciais classificados como mina/nascente não apresentavam captação protegida, sendo que a água escorria pela superfície do terreno (por distâncias variadas, dependendo da propriedade) antes de ser canalizada. Foi constatado, ainda, que em 100\% das propriedades não existia tratamento da água destinada à dessedentação dos animais.

Considerando a prevalência de propriedades positivas para Giardia spp. e Cryptosporidium spp., não foram observadas diferenças entre aquelas que utilizavam manancial superficial ou subterrâneo $(\mathrm{P}>0,05)$, possivelmente pelo número limitado de propriedades investigadas (Tab. 1). Sabe-se que águas subterrâneas, pelo processo de infiltração pelas camadas do solo, apresentam densidade de (oo)cistos de protozoários mais baixa que os mananciais superficiais (Hancock et al., 1997; USEPA, 1998; Gamba al., 2000). Os mananciais superficiais podem, assim, funcionar como prováveis fontes de infecção para os animais, sendo responsáveis, inclusive, pela introdução desses bio-agentes patogênicos nas propriedades e nos rebanhos. Entretanto, neste estudo, não se pode fazer inferência sobre a maior ou menor exposição dos animais à infecção por esses protozoários em função do tipo de manancial de água consumido, pois, mesmo supridos por fontes de água subterrâneas, os animais têm acesso a fontes superficiais nas propriedades ou podem se infectar a partir de outros tipos de exposição, como o solo.

Tabela 1. Prevalência de propriedades positivas para (oo)cistos segundo o tipo de manancial e fonte de água para dessedentação animal, bacia hidrográfica do Ribeirão São Bartolomeu, Viçosa-MG, janeiro de 2003 a janeiro de 2004

\begin{tabular}{cccc}
\hline \multirow{2}{*}{ Manancial/ fonte de água } & \multicolumn{3}{c}{ Propriedades (\%) } \\
\cline { 2 - 4 } & Total & $\begin{array}{c}\text { Positivas para } \\
\text { Giardia } \text { spp. }\end{array}$ & $\begin{array}{c}\text { Positivas para } \\
\text { Cryptosporidium } \text { spp. }\end{array}$ \\
\hline Subterrâneo & 47,6 & 80,0 & 55,0 \\
Mina/nascente & 19,1 & 50,0 & 62,5 \\
Poço artesiano & 7,1 & 66,7 & 33,3 \\
Poço/cisterna & 73,8 & $71,0^{(2)} \mathrm{a}$ & $54,8^{(3)} \mathrm{a}$ \\
Total & & 62,5 & 75,0 \\
Superficial & 21,4 & 50,0 & 0,0 \\
Rio/ribeirão & 4,8 & $60,0 \mathrm{a}$ & $60,0 \mathrm{a}$ \\
Represa & 26,2 & &
\end{tabular}

Considerando o destino dado às fezes dos animais, todos os proprietários relataram utilizálas como adubo em diferentes tipos de plantações. Apenas duas $(4,9 \%)$ propriedades realizavam algum tipo de tratamento (compostagem ou esterqueira), e as restantes $(95,1 \%)$ faziam uso direto sobre o solo.

A pesquisa de protozoários em fezes animais revelou que, durante todo o período, foram identificadas propriedades positivas, onde pelo menos uma categoria animal estava eliminando cistos e/ou oocistos (Tab. 2). Considerando todo o período de coleta, a prevalência média de propriedades positivas foi $36,4 \%$ para Giardia spp. e 18,0\% para Cryptosporidium spp. Com exceção do quarto trimestre do estudo, o porcentual de propriedades positivas foi sempre maior para Giardia spp. que para Cryptosporidium spp. A presença permanente de animais eliminando (oo)cistos de protozoários aponta para a importância que a exploração animal pode desempenhar como possível fonte de contaminação de cursos d'água. 
Tabela 2. Prevalência de propriedade positivas para (oo)cistos de protozoários segundo a categoria animal (bovinos) e a época do ano, bacia hidrográfica do Ribeirão São Bartolomeu, Viçosa, MG, janeiro de 2003 a janeiro de 2004

\begin{tabular}{|c|c|c|c|c|c|}
\hline \multirow{2}{*}{ Categoria animal/protozoário } & \multicolumn{4}{|c|}{ Trimestre $(\%)$} & \multirow{2}{*}{ Média } \\
\hline & $1^{\circ}$ & $2^{\circ}$ & $3^{\circ}$ & $4^{\circ}$ & \\
\hline \multicolumn{6}{|l|}{ Adulto } \\
\hline Cryptosporidium spp. & 17,6 & 17,1 & 17,1 & 11,8 & 15,9 \\
\hline Giardia spp. & 38,2 & 45,7 & 37,1 & 5,9 & 31,9 \\
\hline \multicolumn{6}{|l|}{ Jovem } \\
\hline Cryptosporidium spp. & 17,9 & 18,2 & 19,0 & 25,0 & 19,8 \\
\hline Giardia spp. & 35,7 & 59,1 & 52,4 & 25,0 & 42,9 \\
\hline \multicolumn{6}{|l|}{ Sinal de doença gastroentérica } \\
\hline Cryptosporidium spp. & 50,0 & 50,0 & - $^{(1)}$ & $0,0^{(2)}$ & 30,0 \\
\hline Giardia spp. & 50,0 & 50,0 & - & 25,0 & 40,0 \\
\hline
\end{tabular}

Dentre os três segmentos pesquisados (animais adultos, jovens e com sinais de doença gastroentérica para a espécie bovina), a maior prevalência média para Cryptosporidium spp. foi encontrada no grupo dos animais com sinais de doença gastroentérica $(30,0 \%)$, enquanto, para Giardia spp., o segmento de animais jovens foi o que apresentou maior valor $(42,9 \%)$.

No grupo de animais aparentemente sadios (segmentos adulto e jovem), ambos os protozoários ocorreram com freqüência mais alta nos animais jovens. Esse fato pode estar relacionado à menor imunidade presente nessa faixa etária, coerente com o manejo adotado nas propriedades, isto é, criação conjunta de animais de faixas etárias diversas.

A distribuição das propriedades pesquisadas segundo a localização nas sub-bacias revela que em todas existem propriedades positivas (Tab. 3). Destaca-se a área do Córrego Santa Catarina, onde foi identificado o menor número de propriedades e de propriedades positivas ao longo do período. Na sub-bacia Córrego Antuérpia, destaca-se a presença de uma caprinocultura onde foi identificado Cryptosporidium spp. ao longo de todo o período da pesquisa.

Tabela 3. Médias geométricas do número de (oo)cistos identificados em amostras de água bruta, segundo a sub-bacia e o Ribeirão São Bartolomeu, Viçosa-MG, janeiro de 2003 a janeiro de 2004

\begin{tabular}{|c|c|c|c|c|c|c|}
\hline \multirow{3}{*}{ Sub-bacia } & \multicolumn{2}{|c|}{$\begin{array}{l}\text { Amostras de água } \\
\text { Média geométrica }\end{array}$} & \multicolumn{4}{|c|}{$\begin{array}{l}\text { Número de } \\
\text { propriedades }\end{array}$} \\
\hline & \multirow{2}{*}{$\begin{array}{l}\text { Giardia spp. } \\
\quad(\text { cistos/l) }\end{array}$} & \multirow{2}{*}{$\begin{array}{l}\text { Cryptosporidium } \\
\text { spp. (oocistos/l) }\end{array}$} & \multirow[b]{2}{*}{ Total } & \multirow[b]{2}{*}{$\%$} & \multicolumn{2}{|c|}{ Positivas (\%) } \\
\hline & & & & & $\begin{array}{l}\text { Giardia } \\
\text { spp. }\end{array}$ & $\begin{array}{c}\text { Cryptosporidium } \\
\text { spp. }\end{array}$ \\
\hline Córrego São Lucas & 1,00 & 3,64 & 5 & 12,2 & 50,0 & 25,0 \\
\hline Córrego dos Machados & 4,87 & 3,41 & 6 & 14,6 & 33,3 & 16,7 \\
\hline Córrego Santa Catarina & 1,63 & 1,63 & 2 & 4,9 & 25,0 & 25,0 \\
\hline Córrego Paraíso & 5,66 & 1,00 & 5 & 12,2 & 66,7 & 21,4 \\
\hline Córrego Palmital & 1,00 & 1,97 & 13 & 31,7 & 44,0 & 32,0 \\
\hline Córrego Antuérpia ${ }^{(1)}$ & 7,84 & 6,59 & 4 & 9,8 & 41,7 & 58,3 \\
\hline Córrego Engenho $^{(2)}$ & 5,98 & 14,76 & 6 & 14,6 & 45,4 & 13,6 \\
\hline $\mathrm{RSB}^{(3)}$ & 22,44 & 6,67 & 41 & 100,0 & 45,2 & 25,5 \\
\hline
\end{tabular}

${ }^{(1)}$ Inclui uma caprinocultura e uma suinocultura. ${ }^{(2)}$ Inclui uma suinocultura. ${ }^{(3)} \mathrm{O}$ Ribeirão São Bartolomeu (RSB) recebe o aporte hídrico dos sete córregos. 
A amostra referente à ETE demonstrou grande contribuição da população humana quanto à eliminação de cistos de Giardia spp. (média geométrica $=2,8 \times 10^{4} \quad$ cistos $\left./ 1\right) \quad \mathrm{e}$, conseqüentemente, contaminação do RSB (Tab. 4). Este resultado é parcialmente coerente com o encontrado por Vieira et al. (1999), que identificaram, na bacia do Ribeirão Arrudas no município de Belo Horizonte-MG, concentrações de cistos de Giardia spp. na ordem de $10^{3}$ a 105/1. Entretanto, esses autores identificaram presença de oocistos de Cryptosporidium spp. na ordem de $10^{2}$ a $10^{4} / 1$, diferentemente do verificado neste estudo, em que não foram evidenciados oocistos de Cryptosporidium spp. nas amostras referentes ao efluente do esgoto humano.
Nos efluentes das suinoculturas, foram identificados cistos nas duas coletas realizadas e oocistos em apenas uma (Tab. 4). A suinocultura 1, localizada na sub-bacia Córrego Engenho, tem seu efluente, normalmente, despejado no córrego de mesmo nome da sub-bacia e, de forma eventual, também é destinado à adubação do solo da propriedade e de outras vizinhas, para o plantio de café, sem tratamento prévio. A suinocultura 2 localiza-se na sub-bacia Córrego Antuérpia e estava, no momento das coletas, iniciando o tratamento dos dejetos suínos com lagoas de estabilização, sendo que, durante o período da pesquisa, esse procedimento ainda não estava sendo realizado.

Tabela 4. Cistos de Giardia spp. e oocistos de Cryptosporidium spp. em amostras de esgoto bruto de suínos e efluente de estação de tratamento de esgoto, bacia hidrográfica do Ribeirão São Bartolomeu, Viçosa, MG, janeiro de 2003 a janeiro de 2004

\begin{tabular}{|c|c|c|c|c|c|}
\hline \multirow[b]{2}{*}{ Amostra } & \multicolumn{2}{|c|}{$\begin{array}{c}\text { Coleta } 1 \\
\text { Julho/2003 }\end{array}$} & \multicolumn{2}{|c|}{$\begin{array}{c}\text { Coleta } 2 \\
\text { Janeiro/2004 }\end{array}$} & \multirow{2}{*}{$\begin{array}{c}\text { Média } \\
\text { geométrica } \\
\text { (cistos de } \\
\text { Giardia } \\
\text { spp.) }\end{array}$} \\
\hline & $\begin{array}{c}\text { Giardia } \\
\text { spp. } \\
\text { (cistos/l) }\end{array}$ & $\begin{array}{l}\text { Cryptosporidium } \\
\text { spp. (oocistos/l) }\end{array}$ & $\begin{array}{l}\text { Giardia spp. } \\
\text { (cistos/l) }\end{array}$ & $\begin{array}{l}\text { Cryptosporidium } \\
\text { spp. (oocistos/l) }\end{array}$ & \\
\hline Efluente ETE & 20.700 & 0 & 39.035 & 0 & $28.425,8$ \\
\hline Suinocultura $1^{(1)}$ & 86 & 0 & 450 & 900 & 196,7 \\
\hline Suinocultura $2^{(2)}$ & 156 & 0 & 1.320 & 660 & 453,8 \\
\hline
\end{tabular}

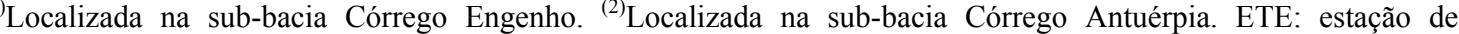
tratamento de esgoto.

Considerando-se os resultados da pesquisa de (oo)cistos nas fezes bovinas e caprinas e os resultados da pesquisa nos efluentes das suinoculturas, verifica-se que ambas as subbacias, Córrego Antuérpia e Córrego Engenho, foram as que mais receberam dejetos de animais contaminados com (oo)cistos de protozoários. Adicionalmente, considerando os resultados quantitativos, a população humana (efluente da ETE) parece contribuir mais com a eliminação de cistos de Giardia spp., e a presença de oocistos de Cryptosporidium spp. seria, em grande parte, oriunda da população animal (suinocultura).

Com relação às amostras de água, as médias geométricas totais para Giardia spp. e Cryptosporidium spp. foram, respectivamente, de 3,93 e 3,62 (oo)cistos/l. A diferença entre as distribuições de ambos os protozoários no período estudado não foi significativa $(\mathrm{F}=0,256$; $\mathrm{P}=0,622$ ) (Tab. 5).

As maiores médias de (oo)cistos coincidiram com os períodos de chuva (primeiro e quarto trimestres) (Fig. 2), e os valores médios de (oo)cistos e de pluviosidade do trimestre de coleta revelaram bom ajuste de correlação $\left(\mathrm{R}^{2}=98,3 \%\right.$; $\mathrm{P}=0,0087$ para Giardia spp. e $\mathrm{R}^{2}=91,8 \% ; \mathrm{P}=0,0421$ para Cryptosporidium spp.). Os resultados encontrados assemelham-se aos de Franco et al. (2001) e Davies et al. (2004), os quais consideraram que, em períodos de chuva, o aumento da turbidez da água, associado ao grande aporte hídrico proveniente do escoamento superficial, incrementa o número de cistos e oocistos, o que confirma a queda na qualidade parasitológica da água bruta durante o período chuvoso. 
Tabela 5. Comparação entre as médias geométricas dos resultados de (oo)cistos de Giardia spp. e Cryptosporidium spp. nas amostras de água bruta considerando todas as sub-bacias, segundo o trimestre de coleta, bacia hidrográfica do Ribeirão São Bartolomeu, Viçosa-MG, janeiro de 2003 a janeiro de 2004

\begin{tabular}{cccc}
\hline \multirow{2}{*}{ Trimestre } & \multicolumn{2}{c}{ Média geométrica } & Valor de $\mathrm{P}^{(1)}$ \\
\cline { 2 - 3 } & $\begin{array}{c}\text { Giardia } \text { spp. } \\
\text { (cistos/1) }\end{array}$ & $\begin{array}{c}\text { Cryptosporidium } \text { spp. } \\
\text { (oocistos/l) }\end{array}$ & \\
\hline Primeiro & 11,28 & 9,20 & 0,353 \\
Segundo & 1,54 & 2,14 & 0,418 \\
Terceiro & 1,42 & 1,52 & 0,464 \\
Quarto & 9,67 & 5,75 & 0,413 \\
\hline Total & 3,93 & 3,62 & 0,622 \\
\hline
\end{tabular}

${ }^{(1)}$ Valores de P para o Teste Wilcoxon, com exceção das médias geométricas totais que foram comparadas pela análise de variância.

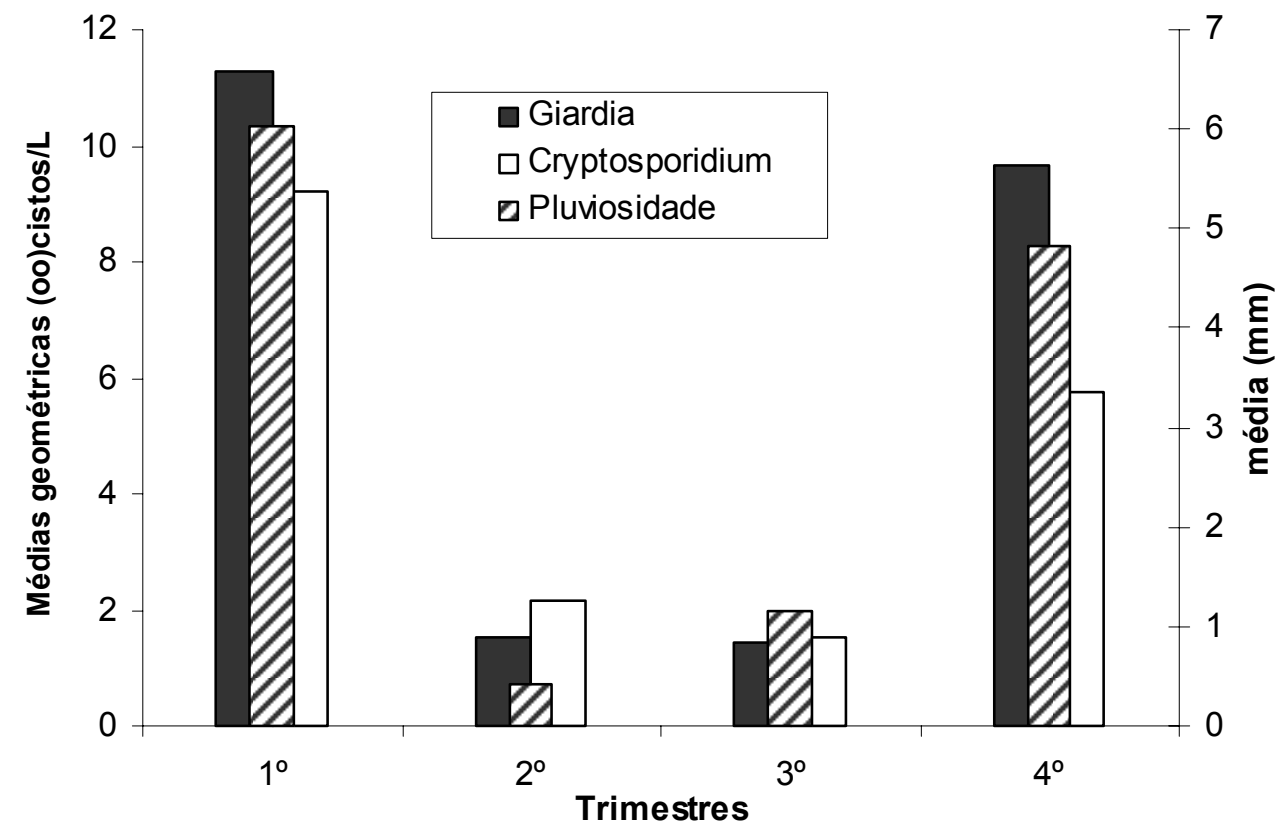

Figura 2. Médias geométricas de cistos de Giardia spp. e oocistos de Cryptosporidium spp. em amostras de água bruta, bacia hidrográfica do Ribeirão São Bartolomeu, Viçosa-MG, janeiro de 2003 a janeiro de 2004.

As sete sub-bacias pesquisadas, em alguma época do ano, apresentaram contaminação com (oo)cistos de protozoários, o que confirma a contribuição dessas com a contaminação do $\mathrm{RSB}$, que recebe todo o aporte hídrico desses cursos d'água (Tab. 3).

As elevadas concentrações de (oo)cistos de Giardia spp. e Cryptosporidium spp. encontradas no RSB revelam preocupação, pois indicam a necessidade de um tratamento da água captada que corresponda à remoção de protozoários tão elevada quanto 4-5 $\log _{10}$, de forma a atender o nível de risco aceitável de $10^{-4}$ de doença na população consumidora, conforme os modelos de avaliação de risco disponíveis (Bevilacqua et al., 2002).

A distribuição de protozoários entre as subbacias não apontou maior ocorrência de protozoários para alguma sub-bacia específica $(\mathrm{T}=8,59 ; \mathrm{P}>0,05$ para Giardia spp. e $\mathrm{T}=5,37$; $\mathrm{P}>0,05$ para Cryptosporidium spp.). Entretanto, podem-se indicar algumas características das áreas que devem auxiliar o entendimento da ocorrência diferenciada, mesmo que não significativa, de (oo)cistos de protozoários entre as sub-bacias pesquisadas. 
A sub-bacia 3, referente ao Córrego Santa Catarina, foi a que apresentou média mais baixa, para ambos os protozoários. Nessa sub-bacia, existe uma área de preservação ambiental, a Mata do Paraíso, com aproximadamente 200 hectares de extensão, sob responsabilidade da Universidade Federal de Viçosa. $\mathrm{Na}$ área do Córrego Santa Catarina, também foi identificado pequeno número de propriedades com exploração animal (Tab. 3). Esses fatos sugerem a necessidade de se proteger as áreas no entorno dos mananciais de abastecimento de água como forma de garantir água de melhor qualidade.

A sub-bacia 6, referente ao Córrego Antuérpia, apresentou alta concentração de protozoários quando comparada às demais sub-bacias. Nessa área, é relevante salientar que a caprinocultura e a suinocultura não realizavam tratamento dos dejetos dos animais e apresentaram, nas análises das fezes (dos caprinos) e no esgoto bruto (dos suínos), (oo)cistos de protozoários (Tab. 3 e 4). Essa constatação indica que as propriedades citadas podem funcionar como possíveis pontos de contaminação do córrego, justificando, assim, as altas concentrações encontradas na água bruta dessa sub-bacia.

A sub-bacia 7, Córrego do Engenho, destacou-se por apresentar maior contaminação ao longo do período estudado, sendo que o padrão de ocorrência de (oo)cistos nessa sub-bacia foi semelhante ao do RSB (Tab. 3). Ressalta-se a existência de uma suinocultura nessa área, cuja análise do esgoto bruto revelou alta concentração de (oo)cistos de protozoários (Tab. 4). Esse fato permite afirmar que explorações animais na área da bacia hidrográfica do RSB sem tratamento adequado dos dejetos colocam em risco a qualidade parasitológica do manancial superficial.

\section{CONCLUSÕES}

Os resultados encontrados confirmam a possibilidade de eliminação de cistos de Giardia spp. e oocistos de Cryptosporidium spp. por diferentes espécies animais e o potencial risco de contaminação de mananciais superficiais, quando da inexistência de tratamento dos dejetos. Aparentemente, a maior contribuição de oocistos de Cryptosporidium spp. parece ser da população animal, uma vez que não foi evidenciado esse protozoário no esgoto doméstico. A contaminação por cistos de Giardia spp. e oocistos de Cryptosporidium spp. identificada na água do Ribeirão São Bartolomeu sinaliza um potencial risco à saúde humana, uma vez que esse ribeirão constitui um dos mananciais de abastecimento de água bruta para a população do município de Viçosa. Essas informações são significativas para o balizamento de políticas públicas relativas às formas de ocupação do solo das bacias de contribuição dos mananciais de abastecimento de água para consumo humano, de forma a controlar e minimizar o deterioramento da qualidade da água, implicando a redução ou prevenção de potenciais riscos de transmissão de doenças às populações consumidoras.

\section{REFRÊNCIAS BIBLIOGRÁFICAS}

ALLEN, M.J.; CLANCY, J.L.; RICE, E.W. The plain, hard truth about pathogen monitoring. $J$. $A W W A$., v.92, p.64-76, 2000.

BASTOS, R.K.X.; BEVILACQUA, P.D.; NASCIMENTO, L.E. et al. Coliformes como indicadores da qualidade da água. Alcance e limitações. In: CONGRESO INTERAMERICANO DE INGENIERIA SANITARIA Y AMBIENTAL, 27., 2000, Porto Alegre. Anais... Rio de Janeiro: AIDIS, 2000. CD-ROM. (Artigo completo).

BASTOS, R.K.X.; HELLER, L; FORMAGGIA, D.M.E. et al. Revisão da Portaria 36 GM/90. Premissas e princípios norteadores. In: CONGRESSO BRASILEIRO DE ENGENHARIA SANITÁRIA E AMBIENTAL, 21., 2001, João Pessoa. Anais... Rio de Janeiro: ABES, 2001. CD-ROM. (Artigo completo).

BEVILACQUA, P.D.; BASTOS, R.K.X.; HELLER, L. et al. Densidades de Giardia e Cryptosporidium em mananciais de abastecimento de água e prevalência de giardíase: usos e aplicações do modelo teórico de avaliação de risco. In: CONGRESO INTERAMERICANO DE INGENIERIA SANITARIA Y AMBIENTAL, 27., 2002, Cancum. Anais... Cancum: AIDIS, 2002. p.1-8. (Artigo completo).

CRAUN, G.F.; HUBBS, S.A.; FROST, F. Waterborne outbreaks of cryptosporidiosis. $J$. AWWA., v.90, p.81-91, 1998.

DAVIES, C.M.; FERGUSON, C.M.; KAUCNER, C. et al. Dispersion and Transport 
of Cryptosporidium Oocysts from Fecal Pat sunder Simulated Rainfall Events. Appl. Environ. Microbiol., v.70, p.1151-1159, 2004.

FAYER, R.; MORGAN, U.; UPTON, S.J. Epidemiology of Cryptosporidium: transmission, detection and identification. Inter. J. Parasitol., v.30, p.1305-1322, 2000.

FRANCO, R.M.B.; ROCHA-EBERHARDT R.; CANTUSIO NETO, R. Ocurrence of Cryptosporidium oocysts and Giardia cysts in raw water from the Atibaia River, Campinas, Brazil. Rev. Inst. Med. Trop. S. Paulo, v.43, p.109-111, 2001.

GAMBA, R.C.; CIAPINA, E.M.P.; ESPÍNDOLA, R.S. et al. Detection of Cryptosporidium sp. oocysts in groundwater for human consumption in Itaquaquecetuba city, S. Paulo-Brazil. Braz. J. Microbiol., v.31, p.23-30, 2000.

HANCOCK, C.M.; ROSE, J.B.; Callahan, M. Cryptosporidium and Giardia in US groundwater. J. AWWA., v.58, p.58-61, 1997.

HELLER, L.; BASTOS, R.K.X.; VIEIRA, M.B.C.M. et al. Oocistos de Cryptosporidium e cistos de Giardia: circulação no ambiente e riscos à saúde humana. Epidemiol. Serv. Saúde, v.13, p.79-92, 2004.

KOSEK, M.; ALCANTARA, C.; LIMA, A.A.M. Cryptosporidiosis: an update. Lancet Infec Dis., v.1, p.262-269, 2001.

NIEMINSKI, E.C.; ONGERTH, J.E. Removing Giardia and Cryptosporidium conventional treatment and direct filtration. J. $A W W A$., v.87, p.90-106, 1995.
OLIVEIRA, A.A. Enteroparasitas em populações usuárias de diferentes sistemas de abastecimento de água em Viçosa-MG. 2004. 146f. Dissertação (Mestrado) - Universidade Federal de Viçosa, Viçosa.

RAMIREZ, N.E.; WARD, L.A.; SREEVATSAN, S. A review of the biology and epidemiology of cryptosporidiosis in humans and animals. Microbiol. Infect., v.6, p.773-785, 2004.

SISTEMA para análises estatísticas - SAEG. Versão 9.1. Viçosa: FUNARBE-UFV, 2007. (CD-ROM).

TZIPORI, S.; WARD, H. Cryptosporidiosis: biology, pathogenesis and disease. Microbiol. Infect., v.4, p.1047-1058, 2002.

VESEY, G.; SLADE, J.S.; BYRNE, M. A new method for the concentration of Cryptosporidium oocysts from water. J. Appl. Bacteriol., v.75, p.82-86, 1993.

VIEIRA, M.B.C.M.; BRITO, L.L.A.; MACHADO, P.M.R. et al. Verificação da ocorrência de cistos de Giardia, oocistos de Cryptosporidium e indicadores bacterianos nos esgotos sanitários da bacia do Ribeirão Arrudas, Belo Horizonte, MG. In: CONGRESSO BRASILEIRO DE ENGENHARIA SANITÁRIA E AMBIENTAL, 20., 1999, Salvador. Anais... Salvador: ABES, 1999. CDROM. (Artigo completo).

XIAO, L.; FAYER, R.; RYAN, U. et al. Cryptosporidium taxonomy: recent advances and implications for public health. Clin. Microbiol. Rev., v.17, p.72-97, 2004. 